\title{
Mechanism of Pneumocystis carinii Attachment to Cultured Rat Alveolar Macrophages
}

Scott T. Pottratz and William J. Martin II

Division of Pulmonary and Critical Care, Department of Internal Medicine,

Indiana University School of Medicine, Indianapolis, Indiana 46202

\begin{abstract}
Pneumocystis carinii (PC) pneumonia begins as an intra-alveolar process resulting in injury to the alveolar epithelium with subsequent invasion of the lung interstitium. The clearance of $\mathrm{PC}$ organisms from the alveolar space is a critical function of alveolar macrophages (AM), the resident alveolar phagocytic cells. In this study the mechanism of PC attachment to $\mathrm{AM}$ was determined using ${ }^{51} \mathrm{Cr}$-labeled organisms, with $P C$ attachment reaching a maximum of $18.9 \pm 2.5 \%$ after 4 h. Attachment was significantly decreased by preincubation of the $A M$ with a monoclonal anti-fibronectin antibody directed against the cell attachment site of fibronectin (from 17.8 $\pm 2.2 \%$ to $8.3 \pm 1.0 \%, P<.0 .01$ ), or by addition of the fibronectin cell binding site analogue Arg-Gly-Asp-Ser (RGDS) (from $18.1 \pm 2.3 \%$ to $2.9 \pm 0.8 \%, P<0.01)$. An anti-fibronectin monoclonal antibody directed against the heparin binding domain of fibronectin had no effect on PC attachment. Addition of the specific calcium ion chelating agent EGTA to the culture media similarly decreased attachment from $16.9 \pm 2.0 \%$ to $5.1 \pm 1.1 \%$ $(P<0.01)$. Fibronectin-mediated attachment of PC to AM did not result in phagocytosis of the organisms by the $A M$ as determined by chemiluminescence measurements. Therefore, the data indicate that PC attachment to $\mathbf{A M}$ is a calcium-dependent process mediated by the cell binding domain of fibronectin which does not trigger a phagocytic response by the AM. (J. Clin. Invest. 1990. 86:1678-1683.) Key words: AIDS - fibronectin - pneumonia - parasite adherence
\end{abstract}

\section{Introduction}

Pneumocystis carinii (PC) ${ }^{1}$ pneumonia is a common and often fatal pulmonary infection in immunocompromised patients. Although recent advances in therapy have improved clinical outcome in these patients $(1,2)$, the basic mechanisms of PC infection remain poorly understood.

PC infection, as measured by the presence of specific antiPC antibodies, is common $(3,4)$, yet the occurrence of clinical disease in the immunologically intact host is unusual. It is likely that PC organisms that enter the alveolus in the normal host are quickly destroyed by alveolar defense mechanisms,

Address reprint requests to Dr. Martin, Division of Pulmonary and Critical Care, Wishard Memorial Hospital OPW 425, 1001 West 10th Street, Indianapolis, IN 46202.

Received for publication 26 February 1990 and in revised form 31 May 1990

1. Abbreviations used in this paper: AM, alveolar macrophage(s); Fn, fibronectin; PC, Pneumocystis carinii.

J. Clin. Invest.

(c) The American Society for Clinical Investigation, Inc.

0021-9738/90/11/1678/06 \$2.00

Volume 86, November 1990, 1678-1683 such as those mediated by the alveolar macrophage (AM). Previous studies have shown that PC organisms bind to AM in vitro, but phagocytosis and subsequent lysis of the organism only occur in the presence of anti-PC antibodies (5). The initial contact of PC organisms with the AM is an essential step in this process, but studies have not yet examined the mechanism of this interaction.

AM express many surface receptors that aid in their ability to bind to microorganisms (6). Among these are receptors for the $F_{c}$ portion of $\operatorname{IgG}(7)$, the complement component $C 3 b(8)$, mannose (9), and fibronectin (Fn) (10). The first two of these ( $F_{c}$ and $C 3 b$ receptors) have been well studied and are known to play important roles in the opsonization of invading microorganisms $(11,12)$. The AM mannose binding protein is thought to aid in the recognition and binding of mannose containing glycoproteins found on the surface of many bacteria and fungi $(13,14)$. The function of Fn receptors on AM is not as clear. Originally, these receptors were thought to serve as a means for binding Fn-coated pathogens (15) that lead to phagocytosis and destruction of the invasive organisms before the onset of a specific immune response. Recent data, however, suggest that Fn, by itself, may possess only weak opsonic activity $(16,17)$, leading to a reevaluation of the function of these receptors.

This study investigated the in vitro interaction of PC obtained from immunosuppressed rats with AM obtained from immunologically intact rats. The attachment of PC organisms to the surface of AM was quantified using ${ }^{51} \mathrm{Cr}$-labeled PC organisms. The data suggest that $\mathrm{PC}$ organisms interact with AM by a Fn- and calcium-dependent process; however this initial PC attachment itself is not sufficient stimulus to produce a phagocytic response by the AM. An improved understanding of the interaction between PC and AM will clarify the mechanisms by which normal AM respond to PC organisms and maintain the alveolar space free of $\mathrm{PC}$ infection.

\section{Methods}

Isolation of Pneumocystis carinii. PC pneumonia was induced in pathogen-free rats by immunosuppression with dexamethasone and transtracheal inoculation of PC organisms as described by Bartlett et al. (18). Female Sprague-Dawley rats (150-175 g, colony 202, Harlan Sprague-Dawley, Inc., Indianapolis, IN) were housed in open cages, and received water containing dexamethasone $2 \mu \mathrm{g} / \mathrm{ml}$, tetracycline $500 \mu \mathrm{g} / \mathrm{ml}$, and nystatin $200 \mathrm{U} / \mathrm{ml}$ ad libitum. Rats were inoculated transtracheally with $1 \times 10^{6} \mathrm{PC}$ organisms 5-7 d after beginning immunosuppression. PC trophozoites were harvested 4-6 wk after inoculation when the rats were moribund with PC pneumonia. Rats were killed by intraperitoneal injection of T-61 euthanasia solution (Taylor Pharmaceutical, Decatur, IL), and the trachea was cannulated following a midline neck incision. The lungs were lavaged six times with 8-ml aliquots of Hanks' balanced salt solution plus $0.6 \mathrm{mM}$ EDTA, penicillin $100 \mathrm{U} / \mathrm{ml}$, streptomycin $100 \mu \mathrm{g} / \mathrm{ml}$, gentamicin $4 \mu \mathrm{g} / \mathrm{ml}$, and amphotericin B $0.5 \mu \mathrm{g} / \mathrm{ml}$ (lavage solution). Approximately $40-45 \mathrm{ml}$ of lavage fluid was obtained from each rat.

PC was purified by a method adapted from Masur and Jones (5). The lavage fluid was centrifuged $(400 \mathrm{~g}$ for $10 \mathrm{~min}$ ) to pellet inflamma- 
tory and alveolar cells, and the supernatant was saved. The pellet was resuspended in lavage solution to prepare cytopreparation smears (Cytospin II, Shandon Southern Instruments Inc., Sewickley, PA). The presence of PC cysts and trophozoites was verified using Gomori methenamine silver stain (19) and Diff-Quik stain (20). To obtain highly purified populations of PC trophozoites, the supernatants were centrifuged $(1,400 \mathrm{~g}$ for $30 \mathrm{~min})$ and resuspended in $1 \mathrm{ml}$ of lavage solution, and PC trophozoites were quantified by the method of Bartlett et al. (21). A typical rat yielded 10-20 × 106 trophozoites. Examination of the trophozoite suspension showed that PC organisms represented $97-98 \%$ of intact cellular material in the suspension. Any samples containing bacterial, fungal, or inflammatory cell contamination were discarded.

$A M$ isolation. Pathogen-free Sprague-Dawley rats were obtained from the same colony as used above. The rats were killed with T-61 euthanasia solution as above and lavaged in a similar manner. The lavage fluid was centrifuged $(600 \mathrm{~g}$ for $10 \mathrm{~min}$ ) to pellet inflammatory and alveolar cells. Cytopreparation smears were prepared as above. Examination of these smears demonstrated $>95 \%$ of the cells obtained to be AM. These cells were then plated at a density of $1 \times 10^{6}$ cells per well in DME (Whittaker-M.A. Bioproducts, Walkersville; MD) supplemented with glutamine $0.6 \mathrm{mg} / \mathrm{ml}$, penicillin $100 \mathrm{U} / \mathrm{ml}$, streptomycin $100 \mu \mathrm{g} / \mathrm{ml}$, gentamicin $4 \mu \mathrm{g} / \mathrm{ml}$, and amphotericin B $0.5 \mu \mathrm{g} / \mathrm{ml}$ on IgG-coated 24-well tissue culture plates and allowed to adhere overnight. IgG-coated plates were utilized to permit adherence of AM to tissue culture plates by a nonfibronectin and noncalcium mediated (22) process. After overnight adherence each well was washed twice with one $\mathrm{ml}$ of DME to remove unattached cells.

Pneumocystis carinii attachment assay. PC attachment to AM was quantified by adapting the ${ }^{51} \mathrm{Cr}$-labeled PC attachment assay developed in our laboratory $(23,24)$. Each experiment was performed in duplicate and repeated on at least five separate occasions. Freshly isolated PC trophozoites were incubated for $18 \mathrm{~h}$ in $2 \mathrm{ml}$ of DME and $50 \mu \mathrm{Ci}$ of $\left[{ }^{5 \mid} \mathrm{Cr}\right]$ sodium chromate (New England Nuclear, Boston, MA). After incubation, the ${ }^{51} \mathrm{Cr}$-labeled $\mathrm{PC}$ suspension was centrifuged (1,400 $\mathrm{g}$ for $15 \mathrm{~min}$ ), the supernatant was discarded, and the pellet was resuspended in DME. The PC suspension was washed four times to remove unincorporated ${ }^{51} \mathrm{Cr}$ and resuspended in $\mathrm{DME}$ at a concentration of $10 \times 10^{6} / \mathrm{ml}$.

Initial studies were performed to determine the time dependency of PC attachment to AM. $2 \times 10^{6}{ }^{51} \mathrm{Cr}$-labeled trophozoites were added to each well of adherent $\mathrm{AM}$ and incubated at $37^{\circ} \mathrm{C}$ for $1,2,4$, or $8 \mathrm{~h}$. After the incubation, the media, containing unattached trophozoites, was removed and saved. The AM cell monolayer, also containing bound trophozoites, was disrupted using 10\% Triton X-100 (Sigma Chemical Co., St. Louis, MO) and saved. ${ }^{51} \mathrm{Cr}$-labeled PC organisms were quantified in each fraction (Beckman model 5500- $\gamma$ counter, Beckman Instruments, Inc., Palo Alto, CA) and percent attachment expressed as follows: Percent attachment $=(A / A+B) \times 100$, where $A$ $={ }^{51} \mathrm{Cr}$-labeled PC bound to the AM and $B={ }^{51} \mathrm{Cr}$-labeled PC free in the media. Attachment was noted to be maximal after $4 \mathrm{~h}$ of incubation and this time was used for all subsequent experiments.

The effect of monoclonal anti-Fn antibodies (Calbiochem-Behring Corp., San Diego, CA) directed against either the cell attachment site of Fn or against the distinct heparin binding site on the Fn molecule was assayed. The antibodies $(0.1 \mathrm{mg} / \mathrm{ml})$ were incubated with the $\mathrm{AM}$ for $1 \mathrm{~h}$. After incubation, unattached antibody was washed away, the ${ }^{51} \mathrm{Cr}$-labeled PC organisms were added to the wells and the attachment assay was performed as above. Control experiments using pooled rabbit serum and IgG were also performed.

The effect of the tetrapeptide molecule Arg-Gly-Asp-Ser (RGDS) was assessed on $\mathrm{PC}$ attachment to $\mathrm{AM}$ by conducting the ${ }^{51} \mathrm{Cr}$-labeled PC attachment assay in the presence of $100 \mu \mathrm{M}$ to $2 \mathrm{mM}$ RGDS (Calbiochem-Behring Corp.). The effect of a similarly structured, control peptide Arg-Gly-Glu-Ser (RGES) was also measured in the attachment assay using the same concentrations.

The effect of calcium-free conditions on PC attachment was also determined using the specific calcium-chelating agent EGTA. The PC attachment assay was conducted in the presence or absence of EGTA using a final concentration of $5 \mathrm{mM}$ which effectively removed all available ionized calcium in the media. Calculation of PC attachment and expression of the data is as described above.

To demonstrate that the measured Fn-mediated PC attachment was to the surface of AM and not to an AM-derived Fn substratum, AM were plated on IgG-coated culture plates and incubated overnight as described previously. Extracellular matrix Fn has been demonstrated to be Triton X-100 insoluble (25); therefore the AM were lysed with $10 \%$ Triton $\mathrm{X}-100$ and the wells washed with DMEM. The ${ }^{51} \mathrm{Cr}$ labeled PC were then added to the wells and allowed to attach for $4 \mathrm{~h}$ as in previous experiments.

Role of AM phagocytosis of PC. To determine the possible effect of AM phagocytosis of PC organisms during the attachment assay, the role of phagocytosis was assessed by two different methods. First, the attachment assay was performed in the presence or absence of potent inhibitors of macrophage phagocytosis, including adenosine (5 mM) and homocysteine $(250 \mu \mathrm{M})(26)$. Secondly, to determine if PC attachment to AM initiated phagocytic activation, phagocytosis was assessed by measurement of luminol-dependent chemiluminescence in a method adapted from Easmon et al. (27). AM were obtained from healthy rats in the same manner as described previously. The AM were suspended in DME $+10 \% \mathrm{FCS}$ at a concentration of $1 \times 10^{6} / \mathrm{ml}$ and $0.5 \mathrm{ml}$ of this solution was added to cuvettes and incubated at $37^{\circ} \mathrm{C}$ for $2 \mathrm{~h}$ to allow AM adherence. After the incubation, $0.2 \mathrm{ml}$ of 5-amino2,3-dihydro-1,4-phthalazinedione (luminol, $5 \times 10^{-3} \mathrm{M}$, Sigma Chemical Co.) was added to each cuvette. Subsequently, the following were added to separate cuvettes to assess their effect on chemiluminescence: $0.2 \mathrm{ml}$ of phorbol 12 -myristate 13 -acetate (PMA) $(0.02 \mathrm{mg} / \mathrm{ml}$, Sigma Chemical Co.), $0.2 \mathrm{ml}$ of PC suspension $\left(20 \times 10^{6} / \mathrm{ml}\right), 0.2 \mathrm{ml}$ of DME as a negative control or $0.2 \mathrm{ml}$ of opsonized zymosan prepared by the method of Easmon et al. (27) as a positive control for phagocytosis (28, 29). Chemiluminescence was measured with a luminometer (model 1251 Wallac, LKB Instruments, Gaithersburg, MD) at 2, 5, 10, 15, 30, $45,60,90,120$, and $240 \mathrm{~min}$ after the addition of the activating agents. Chemiluminescence was measured in $\mathrm{mV}$ and expressed as peak value \pm SEM.

Statistical analysis. The results of each experiment are presented as mean \pm SEM. The attachment data for each experimental condition were evaluated by use of either one-tailed Student $t$ test or analysis of variance with Duncan's test for multiple pairwise comparisons. Statistical significance was accepted for $P<0.05$.

\section{Results}

Initial studies were performed to determine the optimal time required for PC attachment to AM. PC attachment increased up to $4 \mathrm{~h}$ of incubation with the AM, reaching a maximum of $18.9 \pm 2.5 \%$ (Fig. 1). Beyond $4 \mathrm{~h}$ there was no further increase in attachment. There was no evidence of injury to the $\mathrm{PC}$, as measured by percent release of ${ }^{51} \mathrm{Cr}$ from the organisms, for up to $8 \mathrm{~h}$ of incubation with the alveolar macrophages (data not shown). To demonstrate specificity of PC attachment to AM, the assay was repeated in the presence of a 10-fold excess of unlabeled PC organisms. This resulted in a decrease in attachment from $18.9 \pm 2.9$ to $4.6 \pm 1.9 \%(P<0.01)$. PC attachment was not affected by the addition of either $2 \times 10^{6}$ red blood cells $(17.9 \pm 1.7 \%, P<0.5$ compared to control) or the addition of $6.4-\mu \mathrm{m}$ latex beads $(18.8 \pm 2.4 \%, P<0.5)$.

To determine whether a role for Fn exists in the attachment of PC to AM, the effect of monoclonal antibodies directed against the Fn molecule were assessed using the attachment assay. Pretreatment of the AM with a monoclonal antibody directed against the known cell binding site of Fn resulted in a significant decrease in PC attachment to AM 


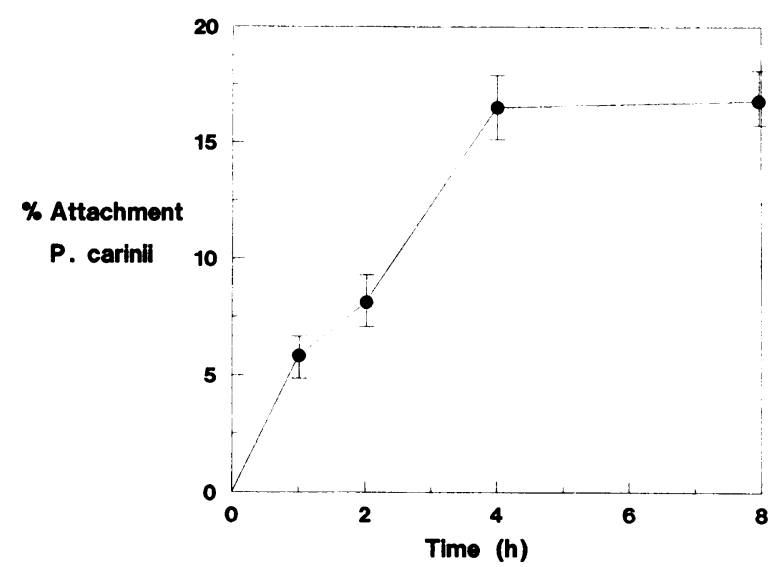

Figure 1. Time dependence of PC attachment to AM. ${ }^{51} \mathrm{Cr}$-labeled PC were added to cultured AM cell monolayers and attachment of the organisms to the AM was then quantified. Attachment of PC was a time-dependent process, reaching a maximum after $4 \mathrm{~h}$ of incubation with AM. All subsequent measurements of $\mathrm{PC}$ attachment to AM were obtained at $4 \mathrm{~h}$. Results are expressed as mean percent attachment \pm SEM.

from $17.8 \pm 2.2$ to $8.3 \pm 1.0 \%$ (Fig. 2 ). In contrast, a monoclonal antibody directed against the heparin binding domain of Fn had no effect on PC attachment (Fig. 2). A control monoclonal antibody directed against the common leukocyte antigen present on macrophages also had no effect on PC attachment (data not shown). Pooled IgG and heat-inactivated preimmune serum similarly did not affect PC attachment to alveolar macrophages (data not shown). Thus, the data suggest the cell binding site of Fn may represent one mechanism for the attachment of PC organisms to AM.

There was no evidence that soluble serum fibronectin affected PC attachment as repeating the assay in serum free conditions did not alter PC attachment $(18.9 \pm 2.9 \%$ in serum, $18.4 \pm 2.0 \%$ without serum, $P>0.5$ ). There was also no evidence that the PC attached to an AM-derived Fn substratum.

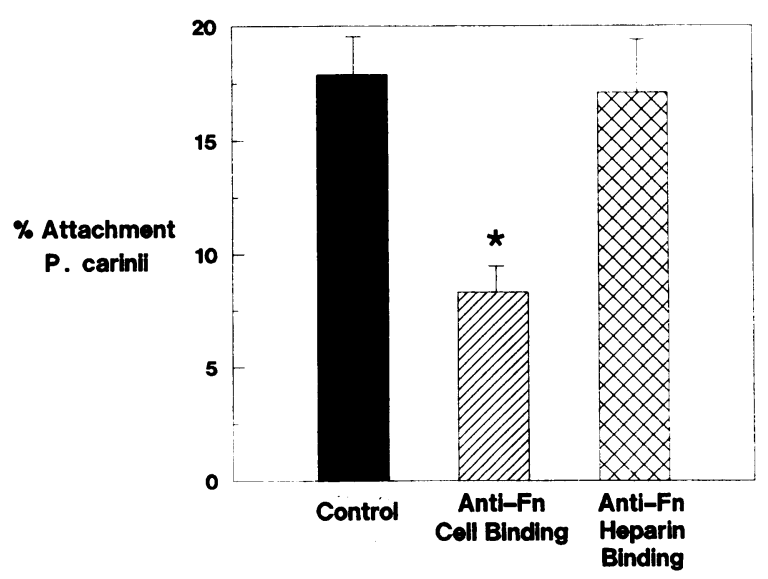

Figure 2. Effect of monoclonal anti-Fn antibodies on PC attachment to AM. Attachment of PC to AM was assessed after preincubation of the AM with either a monoclonal antibody directed against the cell binding site of $\mathrm{Fn}$, or with a monoclonal antibody directed against the heparin binding domain of Fn. Results are expressed as mean \pm SEM. ${ }^{*} P<0.01$.
PC attachment to an AM-derived substratum was virtually undetectable $(1.2 \pm 0.3 \%)$ compared with control attachment to AM $(19.2 \pm 3.2 \%, P<0.0001)$. Therefore, neither serum Fn or an AM derived Fn substratum appeared to be necessary for PC attachment to AM.

Further investigation of the role of the Fn cell binding domain in PC attachment was examined using the tetrapeptides RGDS and RGES. Addition of RGDS, the "true" cell binding site of Fn $(30,31)$, to the PC attachment assay resulted in a marked decrease in PC attachment (Fig. 3). Further, the effects of RGDS were concentration dependent. For example, concentrations of RGDS as low as $0.1 \mathrm{mM}(40 \mu \mathrm{g} / \mathrm{ml})$ caused a significant inhibition of PC attachment to AM's (from $18.1 \pm 2.3$ to $11.2 \pm 1.6 \%, P<0.05)$ but, addition of $2 \mathrm{mM}(800$ $\mu \mathrm{g} / \mathrm{ml})$ RGDS produced maximal inhibition of attachment (from $18.1 \pm 2.3$ to $2.9 \pm 0.8 \%, P<0.01$ ). The similarly structured, but nonfunctional, tetrapeptide RGES (31) was used as a control. In concentrations as high as $2 \mathrm{mM}$, RGES caused no inhibition of PC attachment. These data provide further evidence of the important role of the cell binding domain of Fn in PC attachment to AM.

Fibronectin-mediated cell binding has previously been shown to be dependent on the availability of free calcium ions (32). Addition of the specific calcium chelator EGTA to the assay media (Fig. 4) resulted in a significant decrease in PC attachment (from $16.9 \pm 2.0$ to $5.1 \pm 1.1 \%, P<0.01$ ). There was no evidence of damage to the PC organisms as measured by ${ }^{51} \mathrm{Cr}$ release. The nonspecific divalent cation-chelating agent EDTA also caused a similar decrease in PC attachment (data not shown). Therefore, analagous to other models of Fn-mediated attachment, PC attachment to AM is a calcium-dependent process.

To assess whether phagocytosis of the PC organisms by AM was influencing our measurements of $P C$ attachment, the assay was repeated in the presence of $5 \mathrm{mM}$ adenosine and 250 $\mu \mathrm{M}$ homocysteine, effective inhibitors of macrophage phagocytosis (26). Addition of these agents produced no change in PC attachment to AM (from $18.8 \pm 3.1$ to $17.4 \pm 3.4 \%, P>0.5$ ), indicating that the assay was a measure of $\mathrm{PC}$ attachment only and not a measure of both attached PC and phagocytosed organisms within the AM.

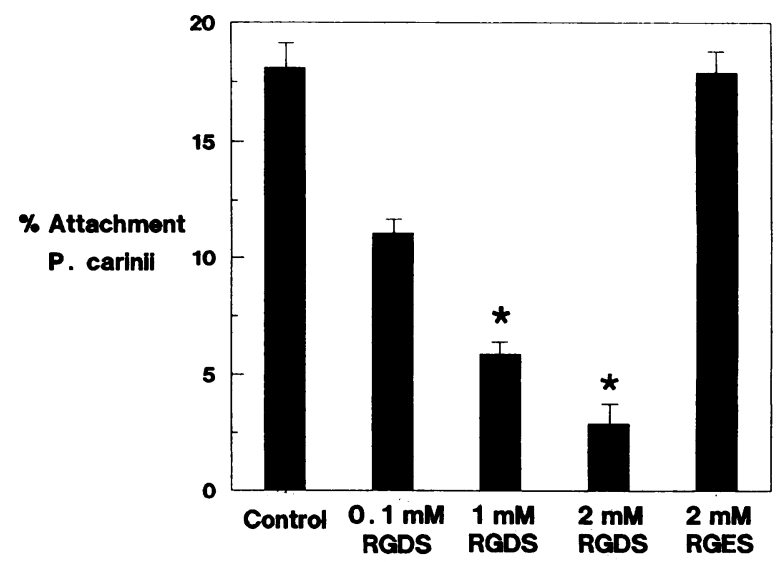

Figure 3. Effect of the tetrapeptides RGDS and RGES on PC attachment to AM. Attachment of PC to AM was quantified after addition of increasing concentrations of the Fn cell binding site analogue RGDS. The tetrapeptide RGES was used as a control. Results are expressed as mean \pm SEM. ${ }^{*} P<0.01$. 


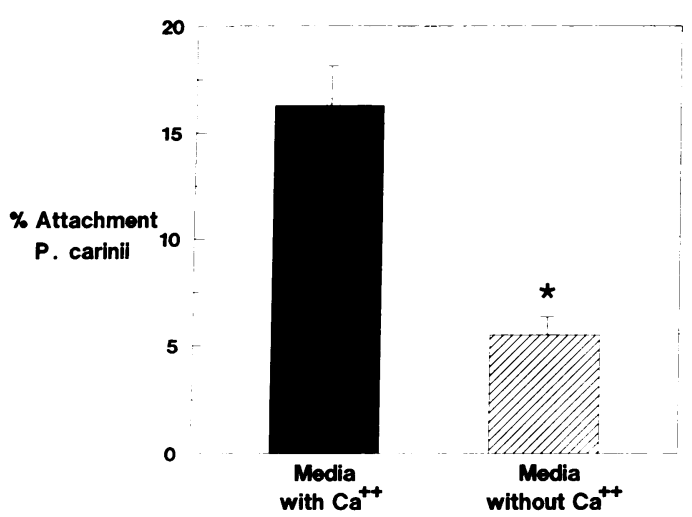

Figure 4. Effect of calcium-free conditions on PC attachment to AM. PC attachment to AM was assessed in the presence or absence of the specific calcium ion-chelating agent EGTA. Results are expressed as mean \pm SEM. ${ }^{*} P<0.01$.

Production of chemiluminescence has previously been correlated with AM phagocytic activity $(27,28)$. Addition of PC to AM with measurement of chemiluminescence for up to four hours demonstrated no increase in chemiluminescent response when compared to AM alone (Fig. 5). In contrast, AM obtained in the same manner and stimulated with PMA or opsonized zymosan produced a marked chemiluminescent response (Fig. 5). Additionally, the presence of adenosine (5 $\mathrm{mM})$ and homocysteine $(250 \mu \mathrm{M})$ blocked the PMA or opsonized zymosan-mediated increase in chemiluminescence. Thus, the process of attachment of PC to AM by itself does not stimulate AM to initiate a phagocytic response against the $\mathrm{PC}$ organisms.

\section{Discussion}

The attachment of PC to AM in vitro was shown to be a time-dependent process, reaching a maximum after $4 \mathrm{~h}$ of incubation. The PC organisms were not injured after their

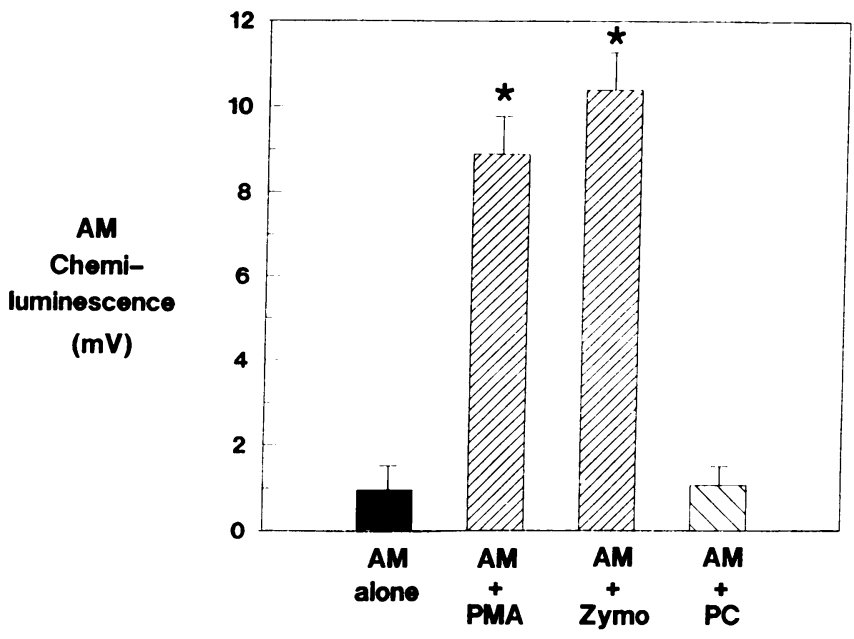

Figure 5. Chemiluminescence production by AM after incubation with PC. Luminol-dependent chemiluminescence of AM was measured for $4 \mathrm{~h}$ after addition of PC. Addition of phorbol myristate acetate $(P M A)$ or opsonized zymosan $(z y m o)$ to the AM was used as a positive control. Results are expressed as mean peak chemiluminescence measurements \pm SEM. ${ }^{*} P<0.01$ compared to AM alone. attachment to the AM. Further, the cell-adhesive glycoprotein Fn appeared to mediate this process via its cell-binding domain. Specific monoclonal antibodies directed against the cell-binding domain of the Fn molecule significantly inhibited PC attachment. Further support for the role of Fn was obtained by the addition of the synthetic tetrapeptide RGDS, the active site of the Fn cell binding domain, which blocked PC attachment. The data also indicate that PC attachment is dependent on the availability of free calcium ions in the media, a finding previously reported as necessary for Fn-mediated attachment (32). Thus, it appears that Fn has an important role in the binding of PC to AM.

Fibronectin is an abundant extracellular matrix glycoprotein with multiple functions in addition to its role in cellular adhesion. Specific cellular receptors for Fn are present on a wide variety of cells including epithelial cells (33), endothelial cells (34), monocytes (10), macrophages (35), lymphocytes (36), and neutrophils (37). These receptors are part of the family of cell membrane receptors known as integrins which serve to anchor cells by providing a connection between extracellular matrix molecules and the cellular cytoskeleton (38). Fn attaches to its cellular receptor via a specific cell-binding domain which has been localized to the four peptide sequence Arg-Gly-Asp-Ser present toward the carboxy terminus of the molecule (30).

Many pathogenic microorganisms bind to Fn to improve pathogen attachment to host cells, an essential process in infection by many organisms. Staphylococcus aureus (39) and streptococcus sp. (40) bind to separate sites at the amino terminus of the Fn molecule. Treponema pallidum (41), Trypanasoma cruzi (42), and Candida albicans (43) have all been shown to use the RGDS cell-binding domain of Fn. Previous work from our laboratory has demonstrated that PC organisms bind to the RGDS binding site of Fn in a saturable and specific manner (24). Additionally, AM also bind Fn via the RGDS cell-binding site, suggesting that Fn may serve as a "bridge" between the PC organisms and the AM.

AM's have been shown to both release Fn extracellularly (44) and to possess surface receptors that bind this molecule (35). The function of the Fn receptors on the AM have not yet been clearly defined. As noted, Fn binds to many pathogenic bacteria, but its role as a possible opsonin remains unclear at this time. Binding of Fn has been reported to cause AM activation leading to phagocytosis of Fn-coated latex beads (15). Other investigators, though, using Fn-coated Staphylococcus aureus have not been able to demonstrate increased uptake of the organisms by AM $(16,17)$.

Our study indicates that Fn-mediated attachment of PC, by itself, is a poor stimulus for phagocytic cell activation. There was no evidence for AM activation following incubation of the AM with PC organisms. Measurement of ${ }^{51} \mathrm{Cr}$ release by the PC organisms was also not affected by incubation with the AM. Prior studies have shown that PC organisms are rapidly degraded after ingestion by AM $(5,45)$. Additionally, PC are susceptible to injury by hydrogen peroxide or superoxide (46), which are products released by AM during phagocytosis. Thus, the data suggest that PC attachment via an Fn-mediated mechanism to AM does not lead to phagocytosis of the organism or activation of the AM.

The mechanism of PC interaction with host inflammatory cells has not previously been investigated. Alveolar clearance of PC in vivo is likely mediated primarily by AM. This study 
examined the in vitro interaction between $\mathrm{PC}$ and normal AM, demonstrating that PC organisms readily attached to AM but were not phagocytosed. It appears that effective host defense against PC infection requires additional mediators for activation of the AM. Absence of these mediators, as documented in many immunodeficiency states, may provide the necessary milieu for active $\mathrm{PC}$ infection. Further investigation of the basic mechanisms of PC pneumonia may lead to new insights into the pathogenesis of this often fatal disease.

\section{Acknowledgments}

This work was supported by a grant (RO1 HL/AI-43524) from the National Institutes of Health. Dr. Pottratz is the recipient of a research fellowship from the American Lung Association.

\section{References}

1. Sattler, F. R., R. Cowan, D. M. Nierem, and J. Ruskin. 1988. Trimethoprim-sulfamethoxazole compared with pentamidine for the treatment of Pneumocystis carinii pneumonia in the acquired immunodeficiency syndrome: a prospective, noncrossover study. Ann. Intern. Med. 107:280-287.

2. Glatt, A. E., K. Chirgmin, and S. H. Landesman. 1988. Treatment of infections associated with HIV infection. N. Engl. J. Med. 318:1439-1448.

3. Meuwissen, J. H., I. Tauber, and A. D. Leeuwenberg. 1977. Parasitologic and serologic observations of infection with pneumocystis in humans. J. Infect. Dis. 136:43-49.

4. Pifer, L. L., W. T. Hughes, S. Stagno, and D. Woods. 1978. Pneumocystis carinii infection; evidence for high prevalence in normal and immunosuppressed children. Pediatrics. 61:35-41.

5. Masur, H., and T. C. Jones. 1978. The interaction in vitro of Pneumocystis carinii with macrophages and L-cells. J. Exp. Med. 147:157-170.

6. Fels, A. O. S., and Z. A. Cohn. 1986. The alveolar macrophage. J. Appl. Physiol. 60:353-369.

7. Naegel, G. P., R. Young, and H. Y. Reynolds. 1984. Receptors for human IgG subclasses on human alveolar macrophages. Am. Rev. Respir. Dis. 129:413-418.

8. Wright, S. D., P. E. Rao, and W. C. Van Voorhis. 1983. Identification of the C3bi receptor of human monocytes and macrophages with monoclonal antibodies. Proc. Natl. Acad. Sci. USA. 80:56995703.

9. Stephenson, J. D., and V. L. Shepherd. 1987. Purification of the human alveolar macrophage mannose receptor. Biochem. Biophys. Res. Commun. 148:883-889.

10. Bevilacqua, M. P., D. Amrani, M. W. Mosesson, and C. Bianco. 1981. Receptor for cold insoluble globulin (plasma fibronectin) on human monocytes. J. Exp. Med. 153:42-48.

11. Mantovani, B., M. Rabinovitch, and V. Nussenzweig. 1972. Phagocytosis of immune complexes by macrophages. J. Exp. Med. 135:780-785.

12. Ehlenberger, A. G., and V. Nussenzweig. 1977. The role for membrane receptors for $\mathrm{C} 3 \mathrm{~b}$ and $\mathrm{C} 3 \mathrm{~d}$ in phagocytosis. J. Exp. Med. 145:357-364.

13. Kan, V. C., and J. E. Bennett. 1988. Lectin-like attachment sites on murine pulmonary alveolar macrophages bind Aspergilus fumigatus conidia. J. Infect. Dis. 158:407-414.

14. Boner, G., A. M. Mhashilkar, M. Rodriguez-Ortego, and N. Sharon. 1989. Lectin-mediated, nonopsonic phagocytosis of Type I Escherichia coli by human peritoneal macrophages of uremic patients treated by peritoneal dialysis. J. Leukocyte Biol. 46:239-245.

15. Gudewicz, P. W., J. Mulnar, M. Z. Lai, D. W. Beezhols, G. E. Seifring, R. B. Credo, and L. Larand. 1980. Fibronectin mediated uptake of gelatin coated latex particles by peritoneal macrophages. $J$. Cell Biol. 87:247-253.
16. Verbrugh, H. A., P. K. Peterson, D. E. Smith, B. T. Nguyen, J. R. Hoidal, B. J. Wilkinson, J. Verhof, and L. T. Furcht. 1983. Human fibronectin binding to staphylococcal surface protein and its relative inefficiency in promoting phagocytosis by human polymorphonuclear leukocytes, monocytes and alveolar macrophages. Infect. Immun. 33:811-820.

17. Yonemasu, K., T. Sasaki, H. Hashimoto, and S. Kashiba. 1988. Opsonic effect of fibronectin on staphylococcal phagocytosis by human polymorphonuclear leukocytes: its relative inefficiency in post-phagocytic metabolic activation and in intracellular killing. Microbiol. Immunol. 32:795-805.

18. Bartlett, M. S., J. A. Fishman, S. A. Queener, M. M. Durkin, M. A. Jay, and J. W. Smith. 1988. New rat model of Pneumocystis carinii pneumonia. J. Clin. Microbiol. 26:1100-1102.

19. Brinn, N. T. 1975. Rapid metallic histological staining. J. Histotechnol. 6:125-129.

20. Cushion, M. T., and P. D. Walzer. 1984. Growth and serial passage of Pneumocystis carinii in A549 cell line. Infect. Immun. 44:245-51.

21. Bartlett, M. S., P. A. Vervanec, and J. W. Smith. 1979. Cultivation of Pneumocystis carinii with WI-38 cells. J. Clin. Microbiol. 10:796-799.

22. Graziano, R. F., D. V. Erbe, and M. W. Fanger. 1989. The mechanisms of antibody-dependent killing mediated by lymphoid and myeloid cells are distinct based on different divalent cation requirements. J. Immunol. 143:3894-3900.

23. Limper, A. H., and W. J. Martin II. 1990. Pneumocystis carinii: inhibition of lung cell growth mediated by parasite attachment. J. Clin. Invest. 85:391-397.

24. Pottratz, S. T., and W. J. Martin II. 1990. Role of fibronectin in Pneumocystis carinii attachment to cultured lung cells. 1990. J. Clin. Invest. 85:351-356.

25. McDonald, J. A. 1988. Extracellular matrix assembly. Annu. Rev. Cell Biol. 4:183-207.

26. Sung, S. S. J., and S. Silverstein. 1985. Inhibition of macrophage phagocytosis by methylation inhibitors. J. Biol. Chem. 260:546-554.

27. Easmon, C. S. F., P. J. Cole, A. J. Williams, and M. Hastings. 1980. The measurement of opsonic and phagocytic function by luminol-dependent chemiluminescence. Immunology. 41:67-74.

28. Thrush, M. A., M. E. Wilson, and K. Van Dyke. 1978. The generation of chemiluminescence by phagocytic cells. Methods Enzymol. 57:462-494.

29. Lin, C. C., W. C. Huang, and C. Y. Lin. 1989. Chemiluminescence and antibody dependent, cell-mediated cytotoxicity between human alveolar macrophages and peripheral blood monocytes in smokers, nonsmokers and lung cancer patients. Chest. 95:553-557.

30. Pierschbacher, M. D., and E. Ruoslahti. 1984. Variants of the cell recognition site of fibronectin that retain attachment-promoting activity. Proc. Natl. Acad. Sci. USA. 81:5985-5988.

31. Yamada, K. M., and D. W. Kennedy. 1985. Amino acid sequence specificities of an adhesive recognition signal. J. Cell. Biochem. 28:99-104.

32. Gailit, J., and E. Ruoslahti. 1988. Regulation of the fibronectin receptor affinity by divalent cations. J. Biol. Chem. 263:12927-12932.

33. Chen, L. B., N. Maitland, P. H. Gallimore, and J. K. McDougall. 1977. Detection of the large external transformation sensitive protein (fibronectin) on some epithelial cells. Exp. Cell Res. 106:3946.

34. Conforti, C., A. Zanetti, S. Colella, M. Abbadini, P. C. Marchisio, R. Pytela, F. Giancotti, G. Tarone, L. R. Languino and E. Dejana. 1989. Interaction of fibronectin with cultured human epithelial cells: characterization of the specific receptor. Blood. 73:1576-1585.

35. Wright, S. D., and B. C. Meyer. 1985. Fibronectin receptor of human macrophages recognizes the sequence Arg-Gly-Asp-Ser. $J$. Exp. Med. 162:762-767.

36. Hemler, M. E., C. Huang, and L. Schwarz. 1987. The VLA protein family: characterization of five distinct cell surface hetero- 
dimers each with a common 130,000 molecular weight B subunit. $J$. Biol. Chem. 262:3300-3309.

37. Nathan, C., S. Srimal, C. Farber, E. Sanchez, L. Kabbash, A. Asch, J. Gailit, and S. D. Wright. 1989. Cytokine-induced respiratory burst of human neutrophils: dependence on extracellular matrix proteins and CD11/CD18 integrins. J. Cell. Biol. 109:1341-1349.

38. Tamkun, J. W., D. W. DeSimone, D. Fonda, R. S. Patel, C. Buck, A. F. Horwitz, and R. O. Hynes. 1986. Structure of integrin, a glycoprotein involved in the transmembrane linkage between fibronectin and actin. Cell. 46:271-282.

39. Kuusela, P. 1978. Fibronectin binds to Staphylococcus aureus. Nature (Lond.). 276:718-720.

40. Simpson, W. A., and E. H. Beachey. 1983. Adherence of Group A streptococci to fibronectin on oral epithelial cells. Inf. Imm 39:275-279.

41. Thomas, D. D., J. B. Baseman, and J. F. Aldrete. 1985. Fibro- nectin mediates Treponema pallidum cytadherence through recognition of fibronectin cell binding domain. J. Exp. Med. 161:514-525.

42. Ouaissi, M. A., D. Afchain, A. Capron, and J. A. Grimaud. 1984. Fibronectin receptors on Trypanasoma cruzi trypomastigotes and their biological function. Nature (Lond.). 308:380-382.

43. Kalo, A., E. Segal, E. Sahar, and D. Dayan. 1988. Interaction of Candida albicans with genital mucosal surfaces: involvement of fibronectin in adherence. J. Infect. Dis. 157:1253-1256.

44. Tsukamoto, Y., W. E. Helsel, and S. M. Wahl. 1981. Macrophage production of fibronectin, a chemoattractant for fibroblasts. $J$. Immunol. 127:673-679.

45. Von Behren, L. A., and E. L. Pesanti. 1978. Uptake and degradation of Pneumocystis carinii by macrophages in vitro. Am. Rev. Respir. Dis. 118:1051-1059.

46. Antony, V. B., K. J. Hadley, R. W. Roeske, D. L. Kachel, and W. J. Martin II. 1990. Mechanism of action of inhaled pentamidine by alveolar macrophages in vivo and in vitro. Clin. Res. 38:135A. (Abstr.) 